University of Nebraska - Lincoln

DigitalCommons@University of Nebraska - Lincoln

Peter Dowben Publications

Research Papers in Physics and Astronomy

November 1998

\title{
Sputter deposition of high resistivity boron carbide
}

\author{
Ahmad A. Ahmad \\ University of Nebraska-Lincoln \\ Natale J. Ianno \\ University of Nebraska-Lincoln, nianno1@unl.edu \\ Seong-Don Hwang \\ University of Nebraska-Lincoln \\ Peter A. Dowben \\ University of Nebraska-Lincoln, pdowben@unl.edu
}

Follow this and additional works at: https://digitalcommons.unl.edu/physicsdowben

Part of the Physics Commons

Ahmad, Ahmad A.; Ianno, Natale J.; Hwang, Seong-Don; and Dowben, Peter A., "Sputter deposition of high resistivity boron carbide" (1998). Peter Dowben Publications. 176.

https://digitalcommons.unl.edu/physicsdowben/176

This Article is brought to you for free and open access by the Research Papers in Physics and Astronomy at DigitalCommons@University of Nebraska - Lincoln. It has been accepted for inclusion in Peter Dowben Publications by an authorized administrator of DigitalCommons@University of Nebraska - Lincoln. 


\title{
Sputter deposition of high resistivity boron carbide
}

\author{
Ahmad A. Ahmad ${ }^{\mathrm{a}, \mathrm{b}}$, N. J. Ianno ${ }^{\mathrm{a}, \mathrm{b}, *}$, Seong-Don Hwang, ${ }^{\mathrm{c}, \mathrm{d}}$, and P. A. Dowben ${ }^{\mathrm{c}, \mathrm{d}}$ \\ ${ }^{a}$ Center for Microelectronic and Optical Materials Research, University of Nebraska-Lincoln, Lincoln, NE 68588-0511 \\ ${ }^{b}$ Department of Electrical Engineering, University of Nebraska-Lincoln, Lincoln, NE 68588-0511 \\ ${ }^{\mathrm{c}}$ Center of Materials Research and Analysis, ,University of Nebraska-Lincoln, Lincoln, NE 68588-0111 \\ ${ }^{\mathrm{d}}$ Department of Physics, University of Nebraska-Lincoln, Lincoln, NE 68588-0111 \\ * Corresponding author. Email: nianno@unlinfo.unl.edu
}

\begin{abstract}
We have succeeded in the rf magnetron sputter deposition of high resistivity boron carbide $\left(\mathrm{B}_{1-x} \mathrm{C}_{x}\right)$. This has been accomplished by the sputter depositing the boron carbide from a methane saturated boron carbide target. We show that the composition and optical band gap of the sputter deposited material are functions of the applied rf power. Furthermore, boron carbide/silicon heterojunction diodes fabricated via sputtering compare favorably with those fabricated from borane cage molecule sources using plasma enhanced chemical vapor deposition (PECVD).
\end{abstract}

Keywords: boron carbide, deposition process, sputtering

\section{Introduction}

In view of the applicability of boron carbide based semiconductor devices in harsh environments, the microstructure and composition of boron carbide phases have been the subject of much investigation, where bulk single crystals, polycrystalline samples [1-6] and thin films [7-13] have been studied. Recently, we have succeeded in depositing high resistivity material via plasma enhanced chemical vapor deposition (PECVD) [7-9], and have fabricated heterojunction diodes and field effect transistors [7, 9, 14-16]. This work details, for the first time, the rf magnetron sputter deposition of high resistivity boron carbides, and the fabrication of boron carbide/silicon heterojunction diodes from the sputter deposited materials.

We have demonstrated that boron-carbide/n-Si(111) heterojunction diodes can be fabricated from closo-1,2-dicarbadodecaborane $\left(\mathrm{C}_{2} \mathrm{~B}_{10} \mathrm{H}_{12}\right.$, orthocarborane $)$ by using synchrotron radiation induced chemical vapor deposition (SR-CVD) [14-16] and plasma enhanced chemical vapor deposition (PECVD) $[15,16]$. The success of these devices is based on the fact that these two deposition methods yield high resistivity $\left(\rho>10^{8} \Omega-\mathrm{cm}\right) \mathrm{B}_{5} \mathrm{C}$ films [7-9]. To date films deposited via sputtering have low resistivities, $\rho<10 \Omega$-cm, and thus do not form rectifying junctions with silicon [17]. In this work, the $\mathrm{B}_{5} \mathrm{C}$ was sputter deposited from a boron carbide $\left(\mathrm{B}_{4} \mathrm{C}\right)$ target previously saturated in a methane plasma. This yielded $\mathrm{B}_{5} \mathrm{C}$ films with resistivities greater than $10^{7} \Omega-\mathrm{cm}$ and rectifying junctions with n-Si(111), n-Si(100), p-Si(100), and p-Si(111).

\section{Experimental apparatus and procedures}

The sputter deposition system consists of a magnetron sputter gun with a $\mathrm{B}_{4} \mathrm{C}$ target operated at $13.56 \mathrm{MHz}$. The system is cryopumped to a base pressure less than $4 \times 10^{-4} \mathrm{~Pa}$. Methane and argon flow through the system and the sputter gun is used to drive a low power $(<100 \mathrm{~W}) 1$ Pa plasma for several hours. After this process is complete, the target is removed from the sputter gun and the hydrogenated carbon layer that deposits on the target surface as a result of the methane/argon plasma is mechanically removed from the target surface. Silicon substrates, $1 \times 1 \mathrm{~cm}$, were chemically etched and cleaned prior to mounting on the substrate holder. Both $\mathrm{p}$ and $\mathrm{n}$ type silicon were mounted simultaneously with a Quartz substrate to provide samples for optical and electrical characterization. The substrate holder is not temperature controlled and is grounded. Boron carbide deposition is then carried out from the saturated target in a pure argon plasma at $0.8 \mathrm{~Pa}$, where the substrate is shuttered off from the sputter gun for $30 \mathrm{~min}$ at the start of each run to allow stable target conditions to be achieved. 


\section{Film characterization}

The deposited films were characterized by Auger electron spectroscopy and depth profiling, optical and infrared absorption and van der Pauw resistivity measurements. Auger electron spectroscopy and depth profiling was calibrated to films deposited via plasma enhanced chemical vapor deposition (PECVD) from closo-1,2,-discarbadodecaborane $\left(\mathrm{C}_{2} \mathrm{~B}_{10} \mathrm{H}_{12}\right)$, where these films were calibrated to $\mathrm{a}_{4} \mathrm{C}$ standard [8]. The film composition was determined by Auger electron spectroscopy after sputtering the surface oxide layer. All films exhibited oxygen levels less than $2 \%$, which is comparable to the (PECVD) films in our previous efforts [8]. Figure 1 shows the composition of the sputter deposited films as a function of applied rf power for an argon pressure of $0.8 \mathrm{~Pa}$ and target substrate spacing of $7.5 \mathrm{~cm}$. The composition can be easily varied from $\mathrm{B}_{1.7} \mathrm{C}$ to $\mathrm{B}_{12} \mathrm{C}$. Auger depth profiling also shows that the films are uniform in composition to within $\pm 5 \%$ through the films [18]. The deposition rate ranged from $0.02 \mathrm{~nm} / \mathrm{s}$ at $50 \mathrm{~W}$ to $0.15 \mathrm{~nm} / \mathrm{s}$ at $250 \mathrm{~W}$, which are comparable to rates observed by others [19]. In order to examine the uniformity of the film composition across the film surface, Auger depth profiling was performed at several different locations on some of the films with the resulting error bars seen in Figure 1. We believe that the initial sputter process with the methane/argon plasma drives a substantial amount of hydrogenated carbon into the near surface of the $\mathrm{B}_{4} \mathrm{C}$ target, possibly creating a hydrogenated boron carbide near surface region. It is from this surface region that sputtering occurs in the pure argon plasma. If this is the case, the composition of the deposited boron carbide might change as a function of time for a fixed input power. In order to investigate this possibility the input power was fixed at $100 \mathrm{~W}$, the argon pressure maintained at $0.8 \mathrm{~Pa}$ and 10 films were deposited in succession with a deposition time of $1 \mathrm{~h}$ per film. The chemical composition of these films, as determined by Auger electron spectroscopy, is plotted as function of total sputtering time in Figure 2a. The composition remains close the value of $\mathrm{B}_{5} \mathrm{C}$ through $6 \mathrm{~h}$ of sputtering and then becomes more carbon rich beyond this point. The target was then conditioned by a methane/argon plasma as previously described and several films were deposited at $100 \mathrm{~W}$ and $0.8 \mathrm{~Pa}$ argon pressure. Figure $2 \mathrm{~b}$ shows the composition of these films, as determined by Auger electron spectroscopy, as a function of total sputtering time. As seen, the composition returns to $\mathrm{B}_{5} \mathrm{C}$. We believe these results indicate that exposure to the methane/argon plasma alters the surface composition of the target, making it more carbon rich. This layer is consumed by sputtering, but can be regenerated by exposure to a methane/argon plasma. The fact that the film composition is a function of power may result from the different sputter yields of boron and carbon as a function of argon ion energy.

The optical absorption measurements were taken on boron carbide films deposited on quartz. From the spectral absorbance data, one can evaluate the optical band gap of the film by plotting $\alpha^{1 / 3}$ vs. $E$, where $\alpha$ is the absorption coefficient and $\mathrm{E}$ is the photon energy, and finding the intercept on the E-axis

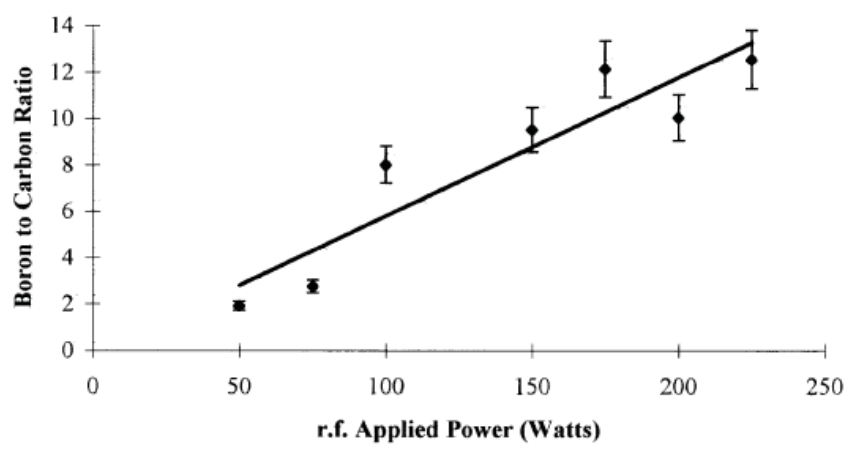

Figure 1. Composition of the sputter deposited films as a function of applied rf power for an argon pressure of $0.8 \mathrm{~Pa}$ and target substrate spacing of $7.5 \mathrm{~cm}$.
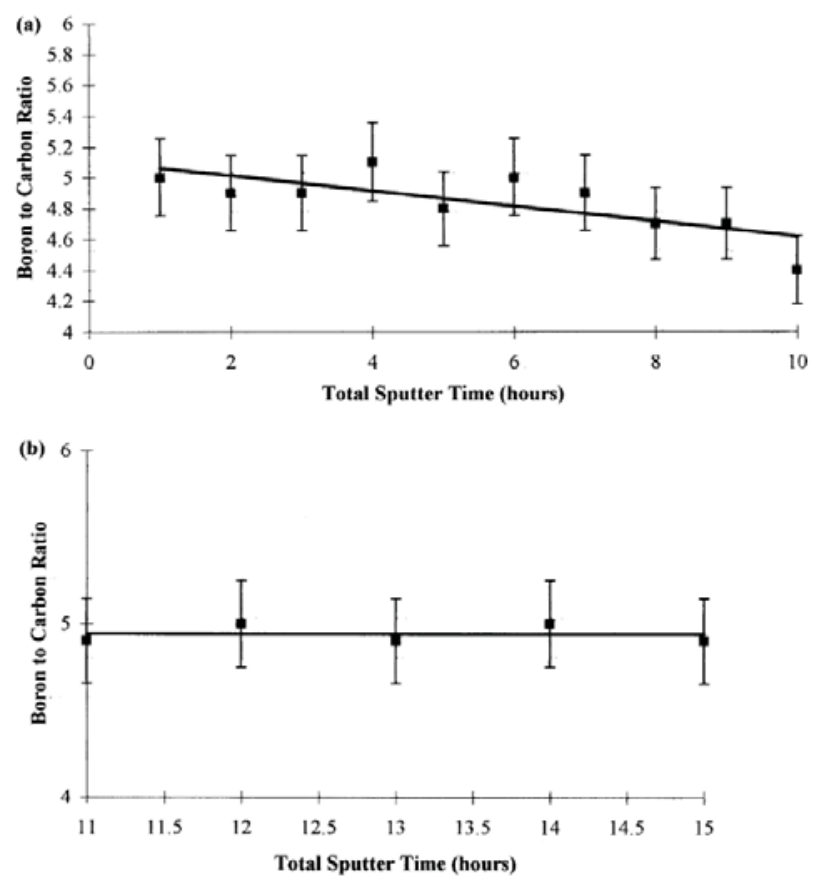

Figure 2. (a) Boron to carbon ratio in deposited films as a function of total target sputter time. (b) Boron to carbon ratio in deposited films as a function of total target sputter time, same target as in (a). In (b) the target was reconditioned with a methane/argon plasma.

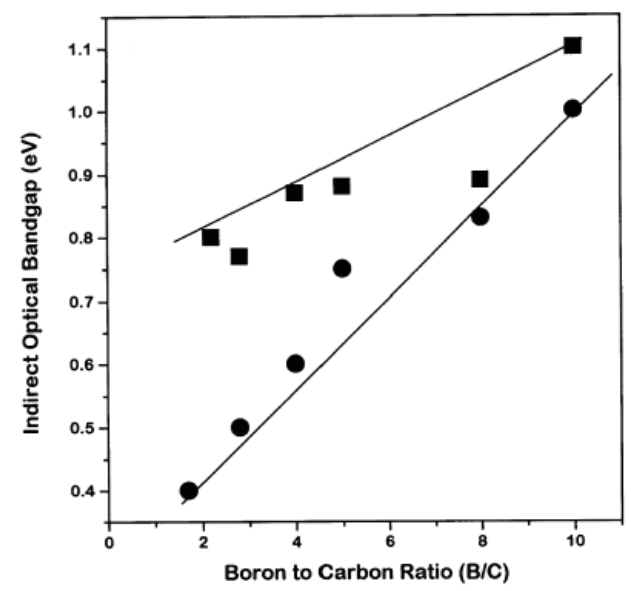

Figure 3. The optical band gap of sputter deposited $(\bullet)$ and PECVD (•) films as a function of composition. 

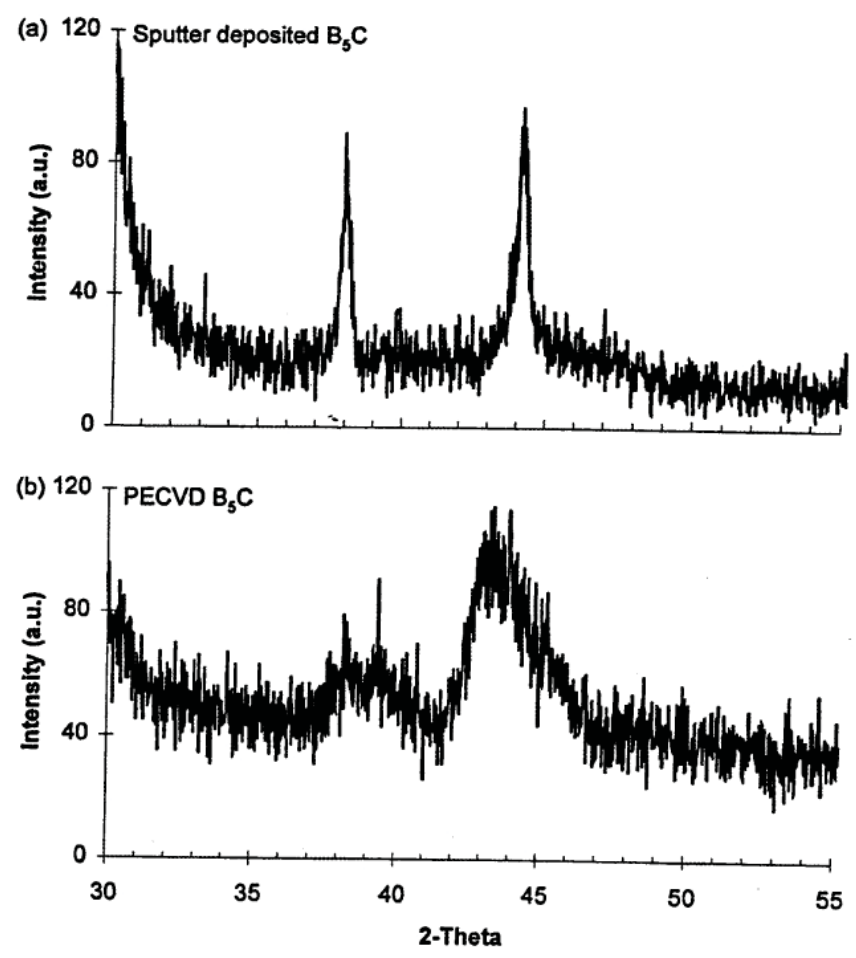

Figure 4. X-ray diffraction pattern for a sputtered deposited $\mathrm{B}_{5} \mathrm{C}$ film (a) and a PECVD deposited $\mathrm{B}_{5} \mathrm{C}$ film (b).

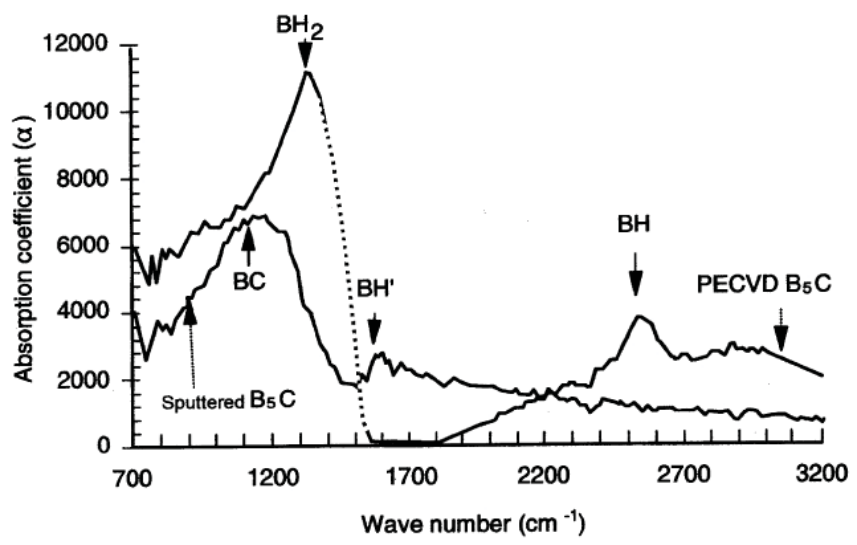

Figure 5. Infrared absorption spectra for sputter deposited and PECVD $\mathrm{B}_{5} \mathrm{C}$ films.

by extrapolating the linear part of the plot. Figure 3 shows the optical band gap of sputter and PECVD deposited films as a function of composition [7]. The sputter deposited films exhibit a consistently lower band gap than the PECVD films.

Figure 4 shows the X-ray diffraction scans obtained using copper $\mathrm{K} \alpha(\lambda=1.54 \mathrm{~nm})$ radiation for a $100 \mathrm{~nm}$ thick sputter deposited $\mathrm{B}_{5} \mathrm{C}$ film and a $\mathrm{B}_{5} \mathrm{C}$ film of similar thickness deposited via PECVD. As seen the $\mathrm{x}$-ray diffraction scans of the sputter deposited and PECVD films exhibit similar peaks, but the sputtered films exhibited sharper, more intense peaks for films of similar thickness. Although no tabulated values for this polytype exist, the d-spacing values of 0.198 and 0.238 $\mathrm{nm}$, respectively, are typical for boro carbide phases $[1-3,5$, 6, 20-22].

As discussed in detail elsewhere [16], the intraicosehedral X-ray diffraction line confirms that the crystallite size of the PECVD material is about $10 \mathrm{~nm}$. For the sputtered thin films the crystallite size is perhaps an order of magnitude larger. This is consistent with our AFM images of the grain boundaries [18].

Finally, the van der Pauw resistivity measurement of the sputter deposited film yielded a resistivity greater than $10^{7} \Omega$ $\mathrm{cm}$, which, although large, is smaller than that observed for PECVD material [7].

A possible explanation for these differences in the band gap, microstructure and resistivity of sputter deposited films can be found in the hydrogen bonding. Figure 5 shows the infrared absorption spectra for sputtered and PECVD deposited $\mathrm{B}_{5} \mathrm{C}$ films. The absorption spectrum of the PECVD film contains only two distinct bands. The main band at about $1325 \mathrm{~cm}^{-1}$ falls in the middle of the $\left(1300-1350 \mathrm{~cm}^{-1}\right)$ assigned to the intraicosahedral modes and possibly exopolyhedral $\mathrm{BH}_{2}$ asymmetric (dipole) modes. It also falls in the absorption band of the $\mathrm{B}-\mathrm{B}$ mode. The second absorption band rises from the $\mathrm{B}-\mathrm{H}$ terminal linkage at $2560 \mathrm{~cm}^{-1}$ [23]. In contrast to this, the major absorption band in the sputter deposited film occurs at $1100 \mathrm{~cm}^{-1}$ which correlates strongly with the amount of carbon present in the film [23] and to various $\mathrm{B}-\mathrm{C}$ vibrations [23-25]. The second absorption band at $1550 \mathrm{~cm}^{-1}$ arises from the stretching of the $\mathrm{B}-\mathrm{H}^{\prime}$ bridge bond. This bond usually prefers to form a three center bond $\left(\mathrm{H}^{\prime}-\mathrm{B}-\mathrm{H}^{\prime}\right)$ and thus is less stable than the $\mathrm{B}-\mathrm{H}$ terminal bond that is observed in the PECVD film. These results clearly show that hydrogen in the PECVD film terminates boron bonds, while in the sputtered film the hydrogen is bound mainly in a bridge structure to boron. Furthermore, the magnitude of the absorption peaks in the PECVD film is considerably larger than those observed in the sputtered film, indicating significantly more hydrogen in the PECVD film. This result is similar to that observed in a-Si:H, where the amount of hydrogen and it's bonding to silicon determine the band gap and resistivity [26-28].

\section{Diode characteristics}

Figure 6 shows the schematic cross-sectional view of the fabricated devices, and the diode $I-V$ characteristics of a $\mathrm{B}_{5} \mathrm{C} /$ $\mathrm{n}-\mathrm{Si}(111)$ structure, and $\mathrm{B}_{5} \mathrm{C} / \mathrm{p}-\mathrm{Si}(111)$ structure, where the $\mathrm{B}_{5} \mathrm{C}$ layer is approximately $60 \mathrm{~nm}$ thick. Although not shown here, $\mathrm{B}_{5} \mathrm{C} / \mathrm{n}-\mathrm{Si}(100)$, and $\mathrm{B}_{5} \mathrm{C} / \mathrm{p}-\mathrm{Si}(100)$ structures exhibit similar characteristics. These structures do not exhibit the classical exponential diode behavior in the forward direction. However, this type of behavior is similar to the previously reported PECVD boron-carbide/n-type $\mathrm{Si}(111)$ heterojunction $[2,7,16]$. 


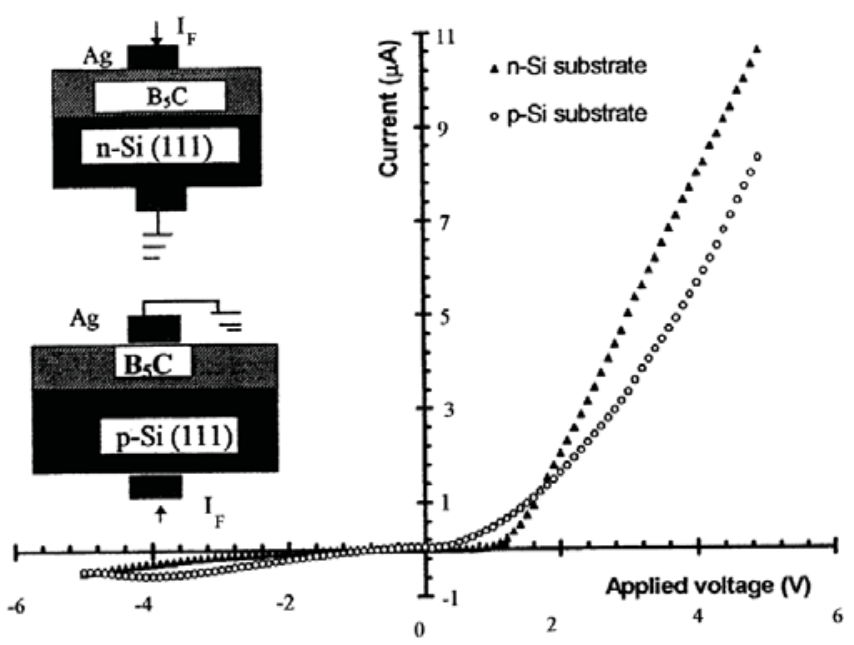

Figure 6. Schematic cross-sectional view of fabricated thin film diodes and biasing configurations. Plots of applied voltage versus current for a $\mathrm{B}_{5} \mathrm{C} / \mathrm{n}-\mathrm{Si}(111)$ diode and for a $\mathrm{B}_{5} \mathrm{C} / \mathrm{p}-\mathrm{Si}(111)$ diode.

\section{Summary}

In summary, we have succeeded in the rf magnetron sputter deposition of high resistivity boron carbides. This has been accomplished by saturating a boron carbide target in a methane plasma, and depositing the boron carbide from the saturated target. The composition and optical band gap are controlled by the rf power, where the optical band gap is consistently smaller than PECVD films of the same composition. The electrical resistivity of sputter deposited $\mathrm{B}_{5} \mathrm{C}$ films is also smaller than a comparable PECVD deposited film, which in part may be due to the smaller band gap. The main peaks found in X-ray diffraction scans of sputter deposited films agree with those obtained from PECVD deposited materials, indicating a similar microstructure. Infrared absorption has shown that the PECVD films contain considerably more hydrogen than the sputtered film. Furthermore, the hydrogen in the PECVD films is bound to carbon in methyl groups, and to boron in a terminal linkage, while in the sputtered films the hydrogen is bound primarily to boron in a bridge structure. Thus the hydrogen in PECVD film may serve to terminate dangling bonds, accounting for increased electrical resistivity and band gap with respect to sputtered films of the same composition. This result is similar to that observed in a-Si:H, where the amount of hydrogen and it's bonding to silicon determine the band gap and resistivity [26-28].

We have also fabricated working heterojunctions between sputter deposited $\mathrm{B}_{5} \mathrm{C}$, and $\mathrm{n}-\mathrm{Si}(111), \mathrm{n}-\mathrm{Si}(100)$, p-Si(100), and $\mathrm{p}-\mathrm{Si}(111)$. The $\mathrm{B}_{5} \mathrm{C} / \mathrm{n}-\mathrm{Si}$ heterojunctions exhibit characteristics similar to PECVD $\mathrm{B}_{5} \mathrm{C} / \mathrm{n}-\mathrm{Si}$ junctions.

\section{Acknowledgements}

This work was supported by AFOSR (Grant No. F49620-94-10433), the Center for Materials Research and Analysis and the
Center for Microelectronic and Optical Materials Research.

\section{References}

1. T. L. Aselage, D. Emin, C. Wood, I. Mackinnon, and I. Howard, MRS Symp. Proc. 97 (1987), p. 27.

2. B. Morosin, T. L. Aselage and R. S. Feigelson, MRS Symp. Proc. 97 (1987), p. 145.

3. H. L. Yakel, Acta Crystallogr. B 31 (1975), p. 1797.

4. A. Kirfel, A. Gupta, and G. Will, Acta Crystallogr. B 35 (1979), p. 1052.

5. G. Will and K. H. Kossobutzki, J. Less-Common Metals 47 (1976), p. 43.

6. G. Will and A. Gupta, J. Less-Common Metals 67 (1979), p. 13.

7. S. Lee, J. Mazurowski, G. Ramseyer, and P. A. Dowben, J. Appl. Phys. 72 (1992), p. 4925.

8. S. Lee, J. Mazurowski, Q. Y. O’Brian, J. J. Tia, Y. Callcott, Y. Tan, K.E. Miyano, D. L. Ederer, D. R. Mueller, and P. A. Dowden, J. Appl. Phys. 74 (1993), p. 6919.

9. S. Lee and P. A. Dowben, Appl. Phys. A 58 (1994), p. 223.

10. A. N. Campbell, A. W. Mullendore, D. R. Tallant, and C. Wood, MRS Symp. Proc. 97 (1987), p. 113.

11. D. N. Rissman, T. J. Rissmann, D. Brewe, and C. Wood, J. Cryst. Growth 74 (1986), p. 210.

12. F. K. Perkins, R. A. Rosenberg, S. Lee, and P. A. Dowben, J. Appl. Phys. 69 (1991), p. 4103.

13. R. A. Rosenberg, F. K. Perkins, D. C. Mancini, G. R. Harp, B. P. Tonner, S. Lee, and P. A. Dowben, Appl. Phys. Lett. 58 (1991), p. 607.

14. D. Byun, S. Hwang, P. A. Dowben, F. K. Perkins, F. Filips, and N. J. Ianno, Appl. Phys. Lett. 64 (1994), p. 1968.

15. S. Hwang, D. Byun, N. J. Ianno, and P. A. Dowben, Appl. Phys. Lett. 68 (1996), p. 1495.

16. D. Byun, B. R. Spady, N. J. Ianno, and P. A. Dowben, NanoStruct. Mat. 5 (1995), p. 465.

17. B. L. Doyle, D. S Walsh, W. R. Wampler, A. K. Hays, H. F. Dylla, D. M. Manos, and S. J. Kilpatrick, in: D. Emin, T. L. Aselage, A. C. Switendick, B. Morosin, and C. L. Beckel (Eds.), AIP Conference Proceedings, Vol. 241, 1991, p. 639.

18. A. Ahmad, Deposition and Characterization of Boron Carbides, Ph.D. Thesis, University of Nebraska-Lincoln, June 1996.

19. M. A. McKernan, Surf. Coat. Technol. 49 (1991), p. 411.

20. T. L. Aselage and D. Emin, AIP Conf. Proc. 213 (1991), p. 177.

21. T. Lundstro, uml;m. AIP Conf. Proc. 213 (1991), p. 186.

22. B. Morosin, T. Aselage, and D. Emin, AIP Conf. Proc. 213 (1991), p. 193.

23. N. A. Blum, C. Feldman, and F. G. Satkiewicz, Phys. Status Solidi A41 (1977), p. 481.

24. H. Tagawa and S. Matsuda, Bull. Chem. Soc. Japan 35 (1962), p. 1424.

25. J. I. Onate, A. Garcia, V. Bellido, and J. L. Viviente, Surf. Coat. Technol. 49 (1991), p. 548.

26. G. Lucovsky and W. B. Pollard, The Physics of Hydrogenated Amorphous Silicon II. In: I. D. Joannopoulos and G. Lucovsky, Editors, Springer, Berlin (1984) p. 301.

27. P. G. LeComber, A. Madan, and W. E. Spear, J. Non-Cryst. Solids 11 (1972), p. 219.

28. P. G. LeComber and W. E. Spear, Phys. Rev. Lett. 25 (1970), p. 509. 